\title{
التو افق الزواجي في ظل وجود طفل توحدي: قراءة نسقية لدراسة حالة أسرة
}

\author{
سـامية رحال \\ جامعة حسيبة بن بوعلي بالشلف- الجزائر \\ samiapsy@gmail.com
}

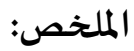

تهدف الدراسة الحالية الى تسليط الضوء على معاش أولياء الأطفال الذين يعانون من طيف التوحد، وذلك بمحاولة التعرف على الصعوبات

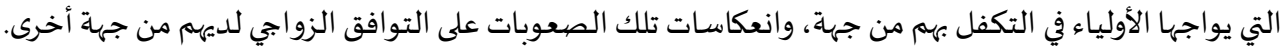

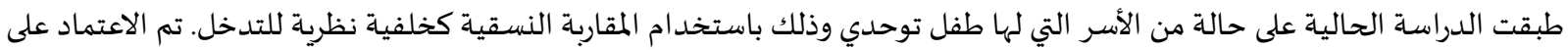

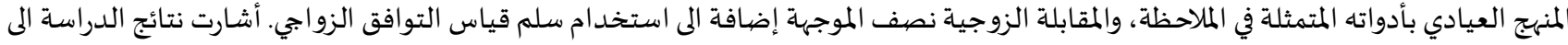
أن صعوبات التكفل بطفل توحدي تنعكس سلبا على التوافق الزواجي لوالديه.

الكلمات المفتاحية: التوافق الزواجي، التوحد، المقاربة النسقية. (c) (1)

مشـكلة الدراسـة:

إن الحياة الأسرية بما تتضمنه من علاقات وتفاعلات مستمرة بين عدة أطراف، ومستويات متفاوتة من الاعتماد المتبادل قد تنطوي على

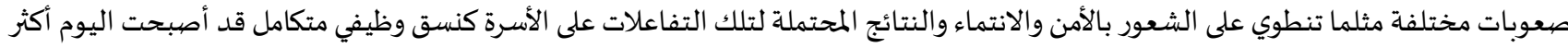
وضوحا بفضل العدد الهائل من البحوث والدراسات العلمية التي أجريت في هذا الصنائ الميدد.

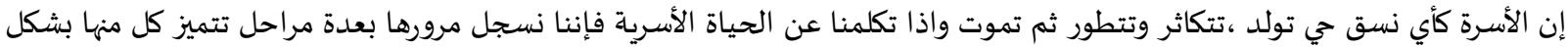

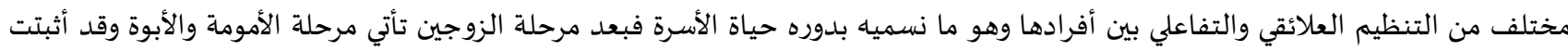

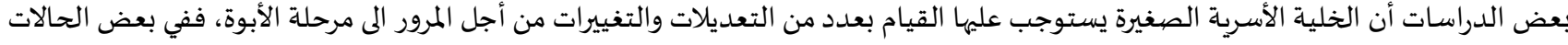

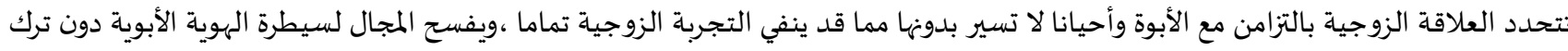

أي مجال للعلاقة مرأة- رجل (Gomes,2007,P18).

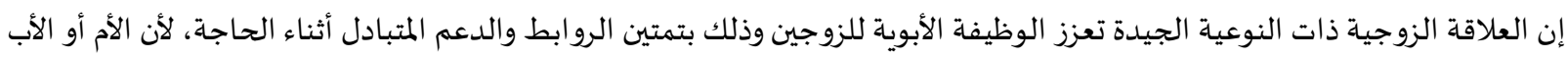

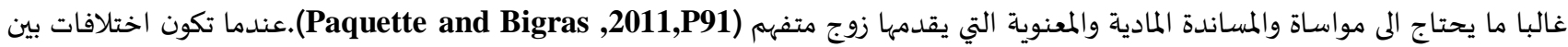

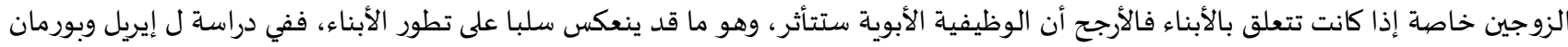
(Erel and Burman,1995)

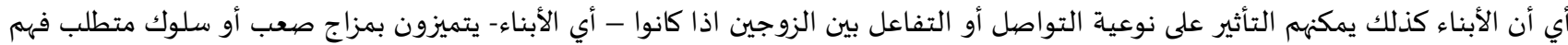

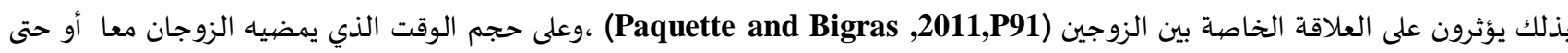

رغبتهم في انجاب أطفال آخرين (Lasselin and al,2012,P48).

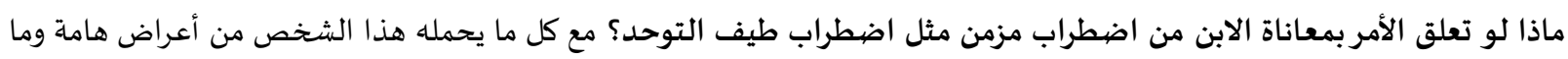

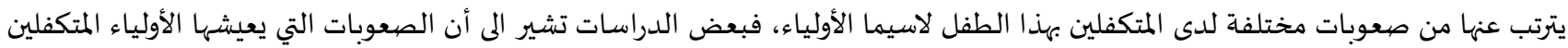

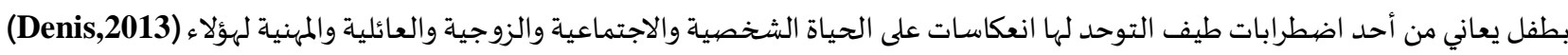

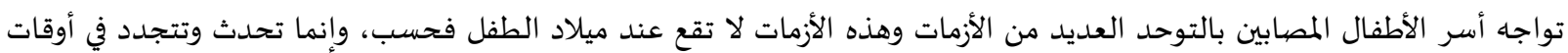

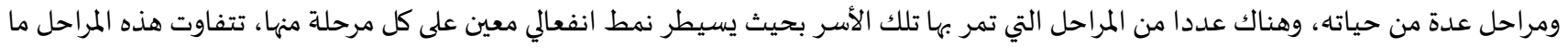

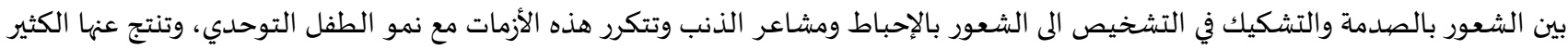
من الضغوط التي تتعرض لها أسرته (الخميسي، (1)). وهذا يعني أن اكتشاف وتشخيص الطفل بأنه توحدي يعد موقفا وحدثا ضاغطا يؤدي الى 
تغيير الأدوار والتوقعات الأسرية وما يصاحب ذلك من ردود أفعال انفعالية، جراء فقدان الأولياء آمالهم وطموحاتهم المرتبطة بميلاد الطفل

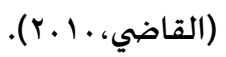

مما سبق جاءت هذه الدراسة لتسليط الضوء على مختلف هذه العلاقات والتغييرات التي تشهدها الأسرة كنسق لا سيما التوافق الزواجي في ظل وجود طفل توحدي. تساؤلات الدراسـة: التساؤل الأول: ماهي صعوبات تكفل الأولياء بطفل مصاب بطيف التوحد؟ التساؤل الثاني: كيف تنعكس صعوبات التكفل بطفل مصاب بطيف التوحد على التوافق الزواجي لوالدياء؟

فرضيات الدراسـة: الفرضية الأولى: تكمن صعوبات التكفل بطفل مصاب بطيف التوحد بشكل رئيسي في الجانب السلوكي للطفل. الفرضية الثانية: تنعكس صعوبات التكفل بطفل مصاب بطيف التوحد سلبا على التوافق الزواجي لوالدياء.

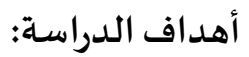

لكل دراسـة أهداف يسعى الباحث الى تحقيقها، وتتمثل أهداف الدراسة الحالية فيما يلي:

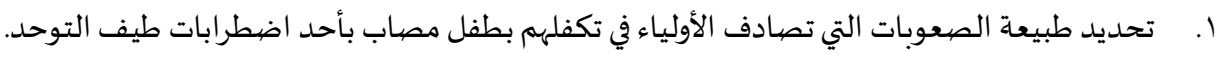
r. معرفة مدى انعكاس الصعوبات المختلفة الناجمة عن التكفل بطفل توحدي على التوافق الزواجي لوالدياء.

أهمية الدراسـة:

تكمن أهمية الدراسة الحالية في: الاهية

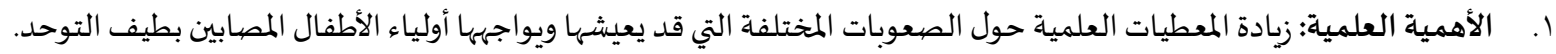

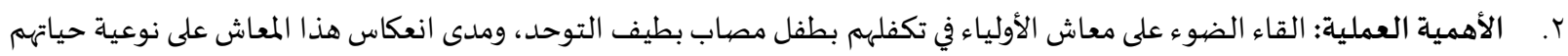
الزوجية، وكذا التعرف على مدى تأثير صعوبات التكفل بطفل توحدي على الصحة النفسية، والجسدية، والسلوكية الصفية لوالدياء.

حدود الدراسـة:

تتمثل حدود الدراسة الحالية فيما يلي:

ا. الحدود الموضوعية: يتمثل موضوع الدراسة الحالية في محاولة التعرف على صعوبات التكفل بطفل مصاب بأحد اضطرابهابة التهات طيف

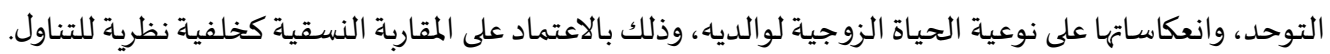

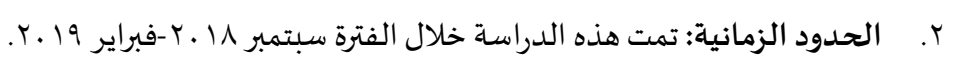
r. الحدود المكانية: تم اجراء الجانب الميداني من هذه الدراسة في مكتب أخصائية المدانية نفسانية تابعة للمركز النفسي البيداغوجي للأطفال المتخلفين ذهنيا بالشلف - الجزائر -

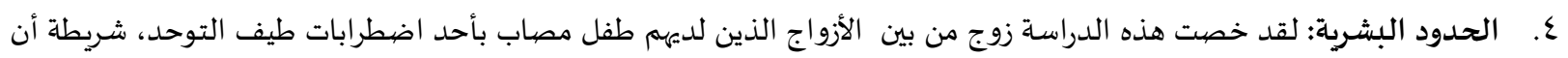

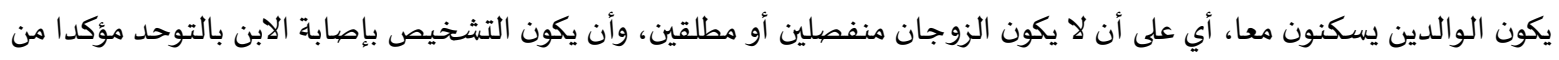

$$
\text { قبل طبيب أخصائي. }
$$

\section{مفاهيم الدراسة ومصطلحاتها:}

التو التو افق الزواجي (The marital adjustment)

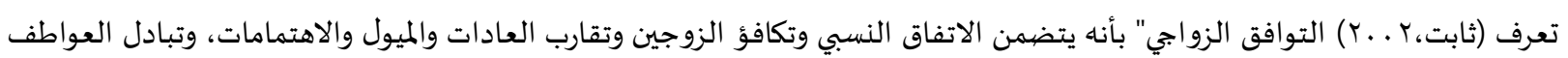

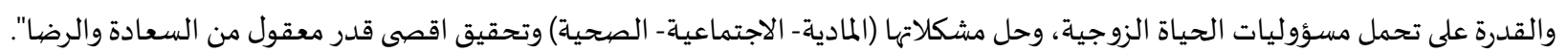

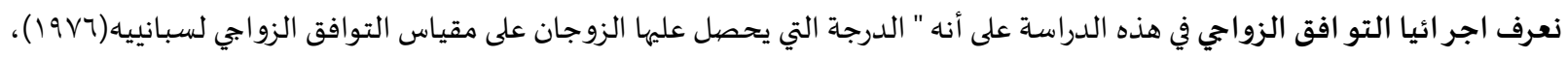

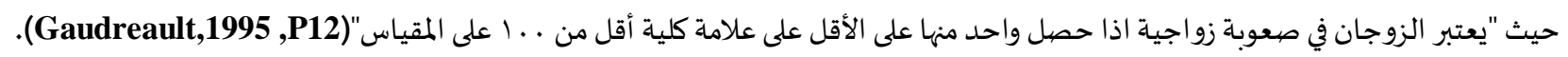


r. (Autism spectrum disorder) اضطراب طيف التوحد )

تعرف المراجعة العاشرة للتصنيف العالهي للاضطرابات (CIM10) اضطراب طيف التوحد، على أنه اضطراب مجتاح للنمو (T.E.D)، يتميز

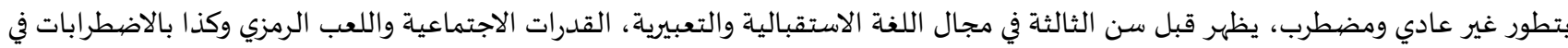
الخصائص الوظيفية للميادين السيكوباثولوجية الثلاثة الآتية: التفاعل الاجتماعي المتبادل- التواصل- محدودية السلوك والنمطية التمبية والتكرار Gayda)

.and Lebovici ,2000,P20) أما اجر ائيا فنقصد باضطراب طيف التوحد هو كل اضطراب تم تشخيصها من طرف أخصائيين في الطب العقلي للأطفال، أو مختصين

اكلينيكيين على أنه تناذر توحدي) (Syndrome autistique) .

r. أمقاربة النسقية (The systems approach)

يعرف فونتان (Fontaine) التناول النسقي أو العائلي، بأنه طريقة علاجية وممارسة تتميز على الأغلب بحجمها ( العمل مع كل أفراد العائلة في

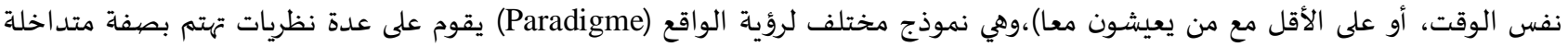

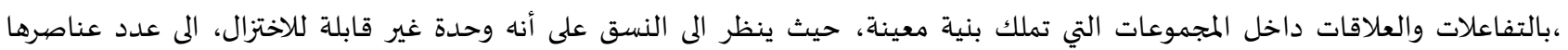

(Satir,1995)

اجر ائيا تم استعمال التناول النسقي في الدراسة الحالية متبنين في ذلك الاتجاه البنيوي لمنوشيين (S. Minuchin) الذي يهتم ببنية العائلة

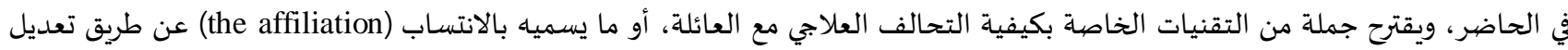

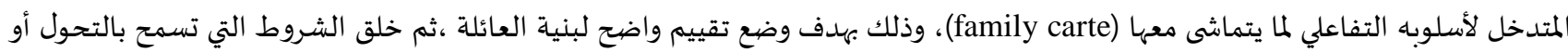

التغير.

$$
\begin{aligned}
& \text { الإطار النظري للدراسة: } \\
& \text { ا. التو افق الزواجي: } \\
& \text { 1,1 مفهوم التو افق الزواجي: }
\end{aligned}
$$

التوافق الزواجي هو درجة الشعور بالتواصل الفكري والعاطفي مع الطرف الآخر في العلاقة الزوجية، بما يحقق لكلا الطرفين أساليب توافقية

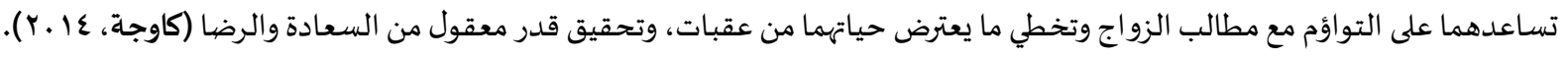

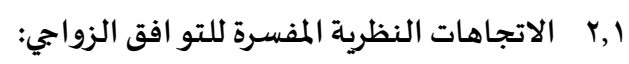

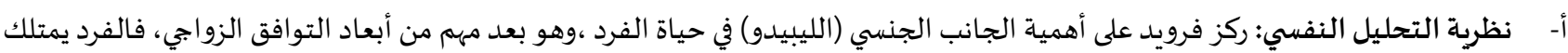

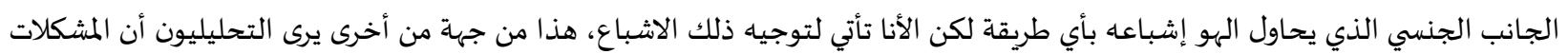

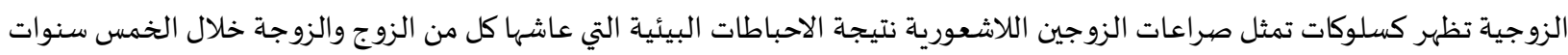

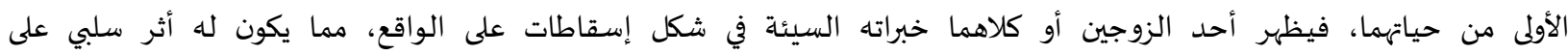

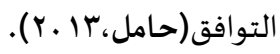

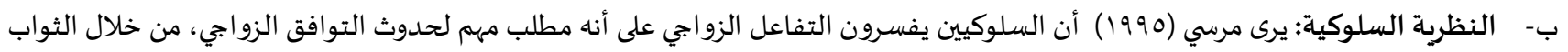

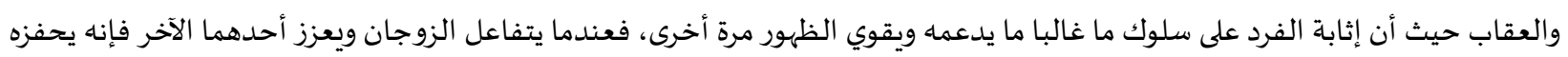

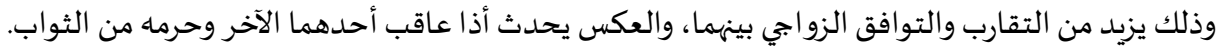

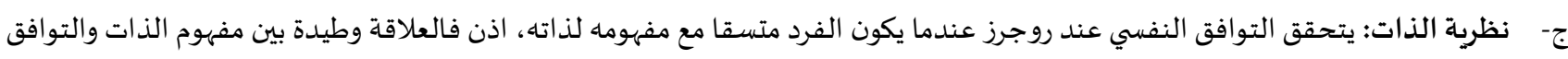

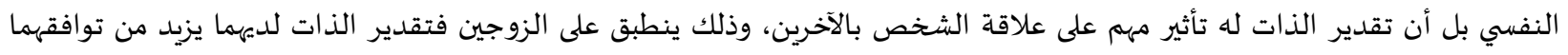

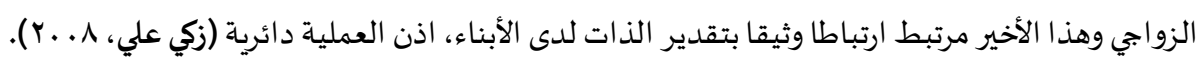

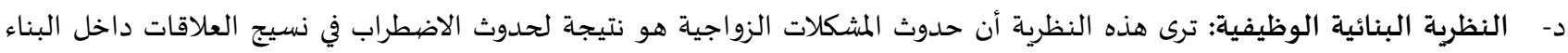

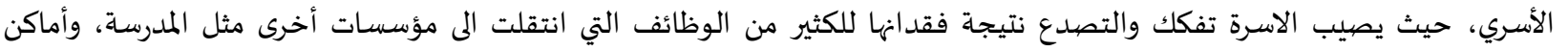

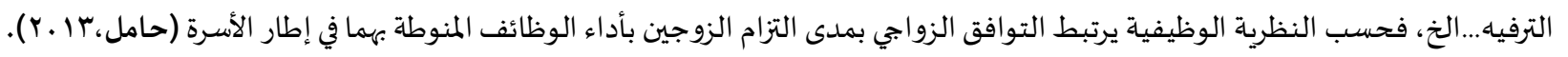

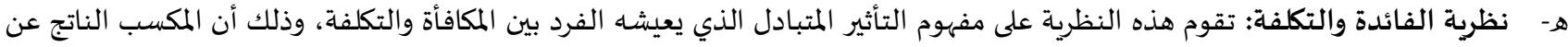

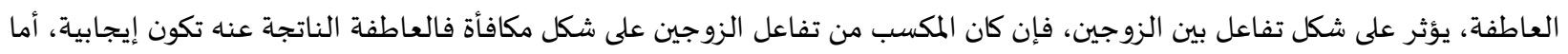
إذا كان المكسب من التفاعل في شكل تكلفة فإن العاطفة تكون سلبية (الشهري، ج . ب). 
و- نظرية الدور: يذهب أنصار هذه النظرية التي تعتبر من النظريات الهامة في دراسة الاسرة الى أن نشأة الخلافات الزوجية يأتي من تعارض توقعات

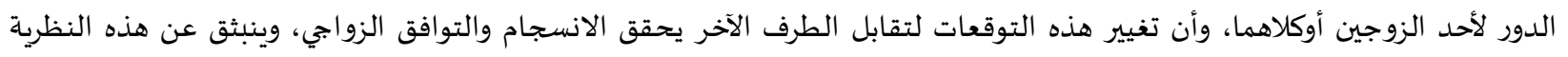

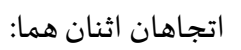

الاتجاه التفاعلي الرمزي: الذي يرى أن التوافق الزواجي يتحدد في درجة تحقق ما تتوقعه الزوجة من زوجها، وحقيقة ما يدركه الزوج في

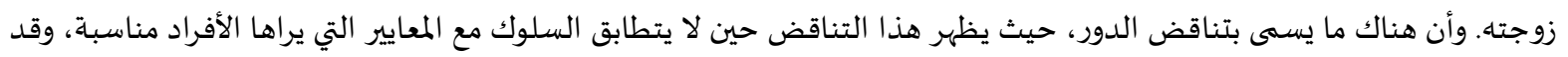
يرجع الخلاف الذي يحدث بين الزوجين المى عدم تقابل الرغبات المختلفة والمتطورة لأحد الطرفين.

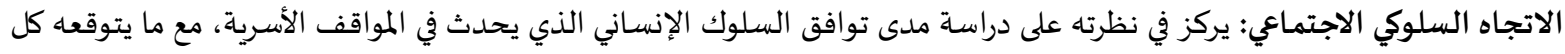

$$
\begin{aligned}
& \text { طرف في العلاقة الزوجية(حامل،با. .r). } \\
& \text { r. . اضطر ابات طيف التوحد } \\
& \text { r, الت التعريف والتصنيف: }
\end{aligned}
$$

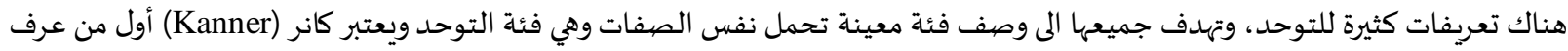

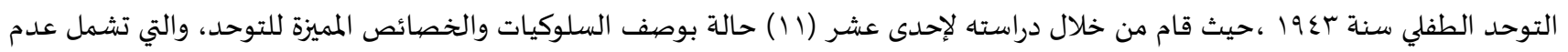

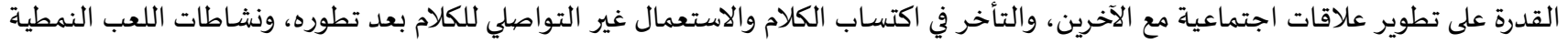

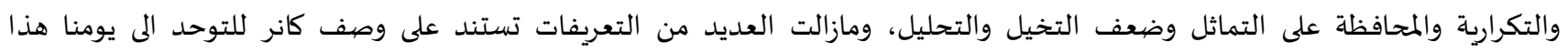

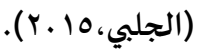
إن تصنيف(CIM 10 (CIM) يصف ثماني مجموعات من الاضطرابات المجتاحة للطفولة وهي: التوحد الطفلي، متلازمة ريت، الاضطراب التفككي للطفولة، فرط الحركة المصحوبة بالتأخر الذهني وبالحركات النمطية، متلازمة اسبرجر، الاضطرابات المجتاحة للنمو غير المحددة.

(Marot,2013)

أما تصنيف (DSM-IV,1994) فيصف خمس مجموعات وهي: الاضطراب التوحدي، متلازمة ريت، الاضطراب التفككي للطفولة، متلازمة

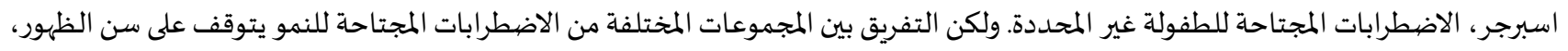

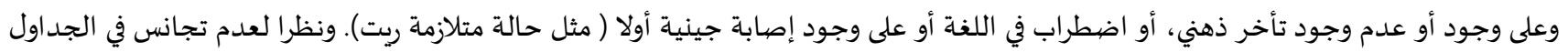

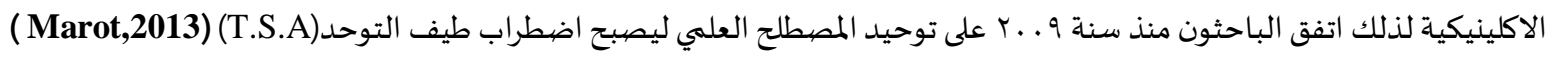

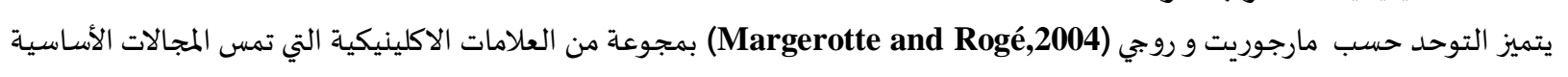

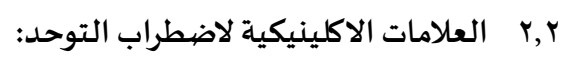
التالية:

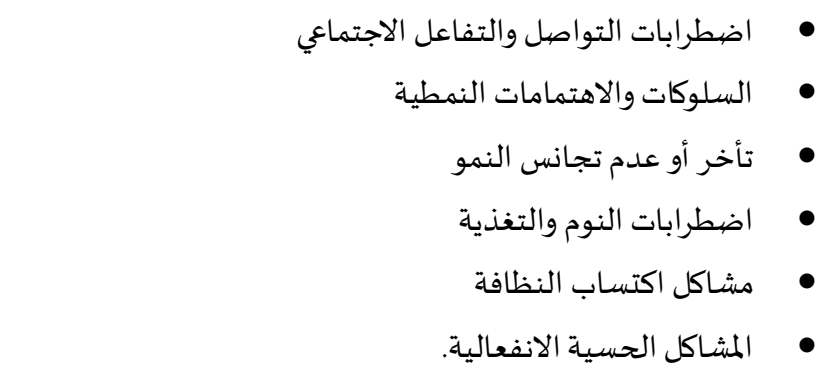

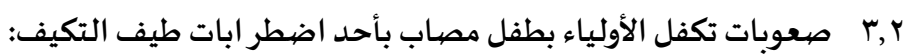

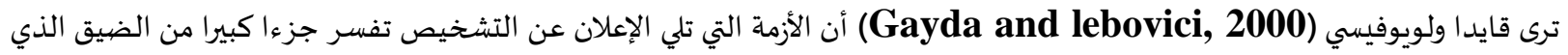

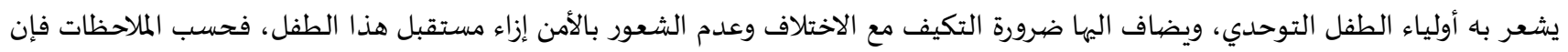

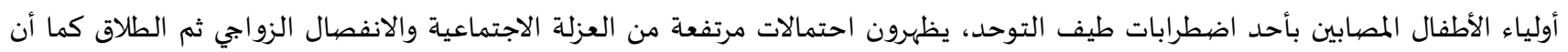

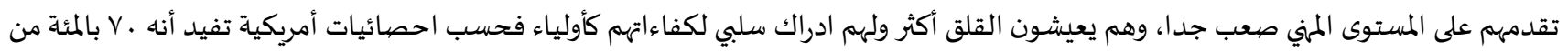

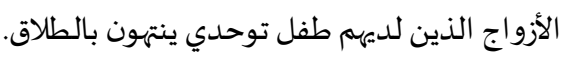

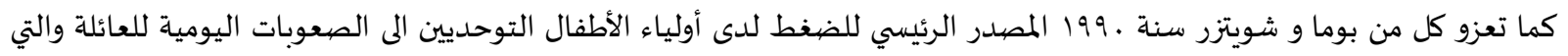

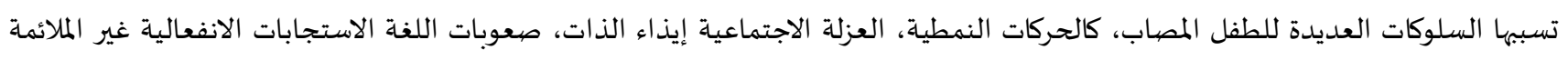


Denis, ) الاستجابات الغرببة للمثيرات الحسية، قصهور القدرات الاجتماعية وكذا القصور في كفاءات العناية بالذات والتبعية الدائمة للأولياء

وتضيف سينيشال وديريفيير(Sénéchal and des Rivières-Pigeon, 2009) من خلال دراستهما أن العلاقة طفل _أولياء قد تصبح هي نفسها مصدرا للضغط ،فالتفاعل التلقائي الذي يعيشه الأفراد في أي سياق أسري طبيعي يصبح منظما وآليا، وكل ما يحدث يأخذ صبغة حل حل لمشكل،

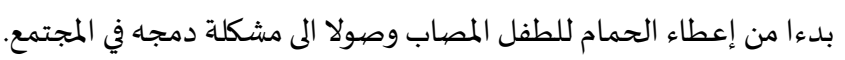
في نفس السياق أشارت جارسين و موكسنس (Garcin and Moxness, 2013) أن نتائج دراسات عديدة تفيد بأنه إذا كان الطفل المصاب

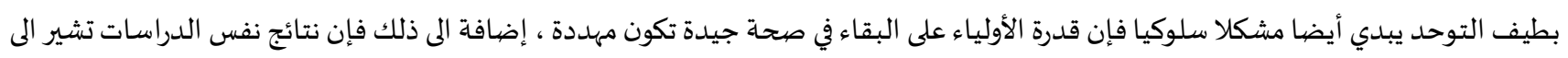

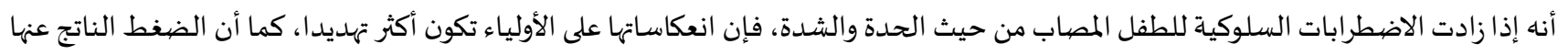

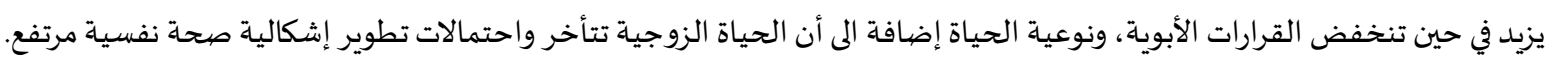

r. المرجعية النظرية للدراسـة الحالية:

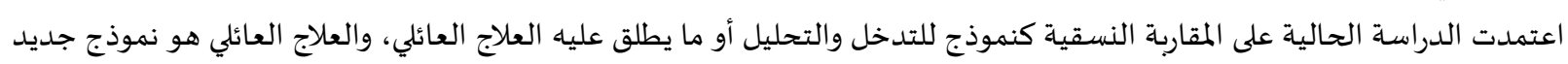
لرؤية الواقع (Un paradigme) بمعنى أنها نظام مرجعي يكشف لنا عن المعطيات بصورة مفهومة، وينظمها وفق طريقة جديدة، كما أنها يقترح تفسيرا جديدا وأهدافا مختلفة للعلاج، فأفراد العائلة بالنسبة للنموذج النسقي يشكلون عناصر سلهر سلسلة دائرية من التفاعلات حيث يؤثر سلوك الفرد بالضرورة على سلوك الآخرين(Stierlin and al,1979).

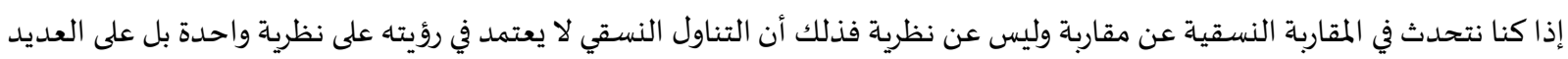

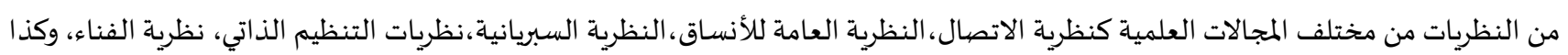

نظريات أخرى (Rougeul,2003,P5).

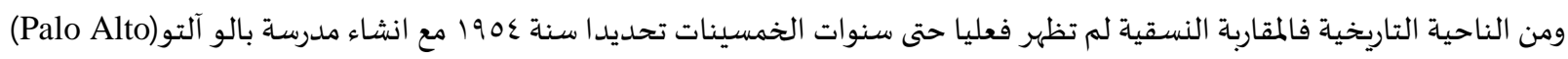
في كاليفورنيا بالولايات المتحدة الأمريكية، وهي عبارة عن فريق بحث ضاحم المدارية المديد من الباحثين من تخصصيات مختلفة، ركز في أبحاثه الأولى على عائلات

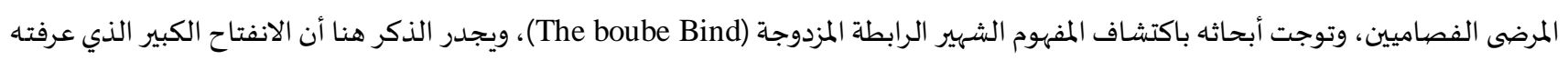
العلاجات العائلية النسقية يدين بالكثير لتيار (Child Guidance Mouvement) الذي كانت تقوده جمعيات مساعدة العائيات بألات في صعوبة، وكذا تأثير ظهور بعض المفاهيم الأنثروبولوجية الجديدة، وكذا ظهور نظرية الأنساق والنظرية السبريانية ( Elkaim,1995).

لماذا التناول النسقي لدراسة مشاكل الأزواج؟ باج

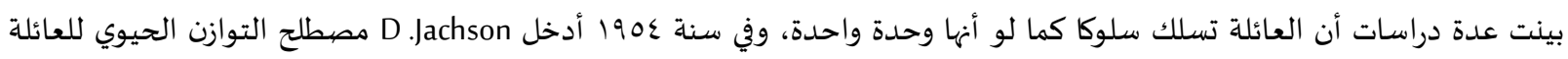

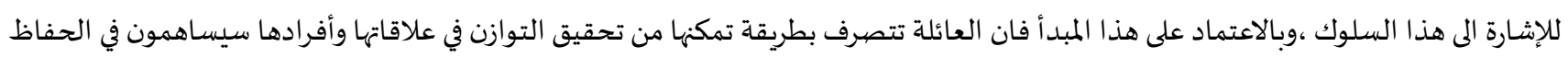

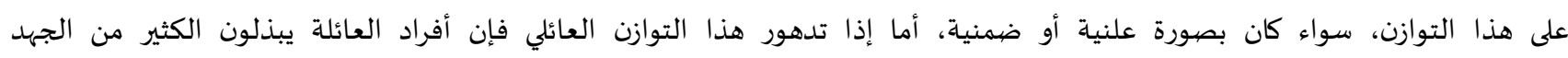
لاسترجاعـاء(Satir,1995,P13). وعليه تؤثر العلاقة الزوجية بشكل كبير على نوع التوازن الحيوي للعائلة لأنها المحور الذي تتشكل حوله باقي العلاقات، وعليه فإن علاقات

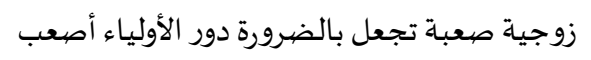
الدراسات السابقة: قام كل من كنستنتاريس وهماتيدس (Konstantareas and Hamotidis,1988) بدراسة هدفت الى اختبار شدة أعراض التوحد وعلاقتها

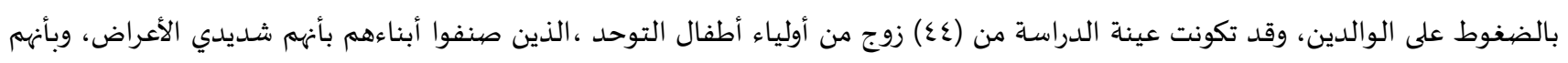

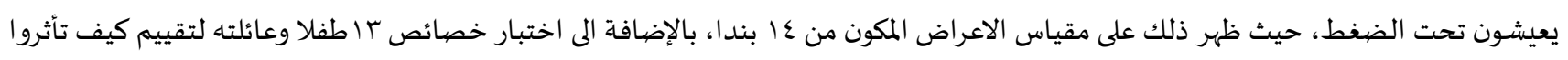

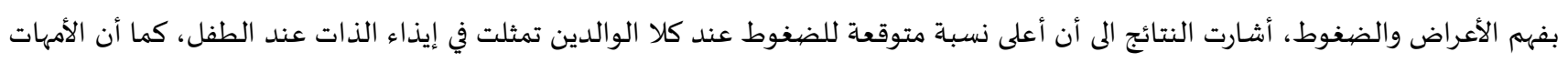
أظهرن الحاجة الى دعم إضافي أكثر من الآباء.

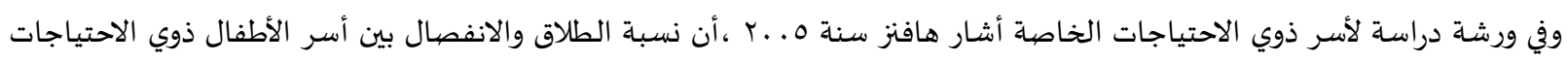

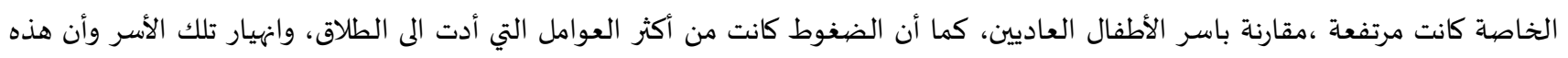

الضغوط تؤثر على العلاقات الشخصية وعلى التفاعل الاجتماعي، وتزيد من عزلة الوالدين الاجتماعية (Divan and al,2012). 


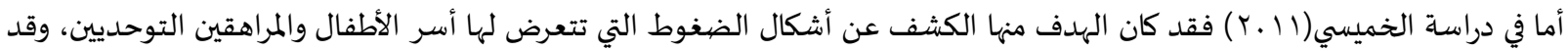

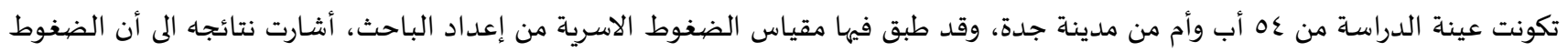

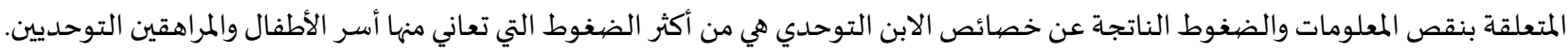

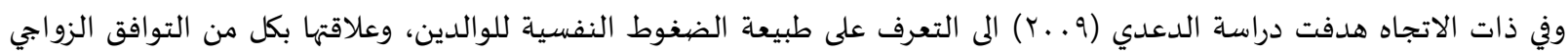

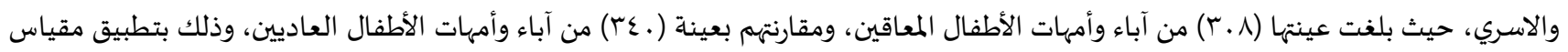

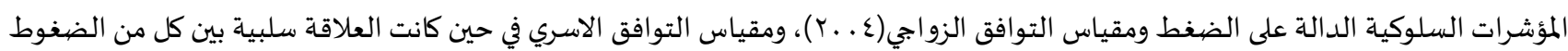

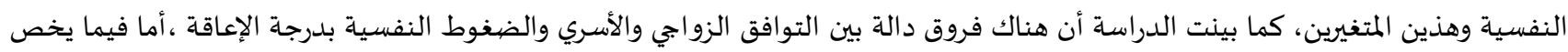

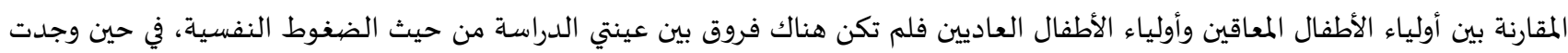
فروق بين العينتين في كل من التوافق الزواجي.

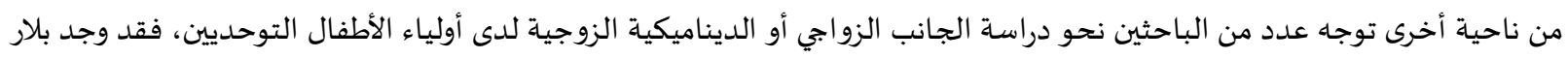

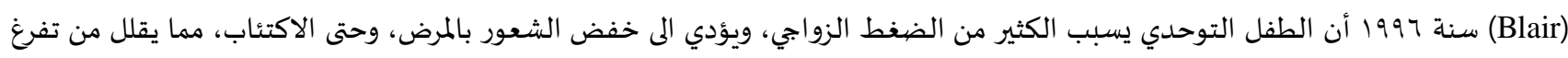

الأولياء لأبنائهم الآخرين ولحياتهم الزوجية (Sénéchal, Des Rivières pigeons,2009).

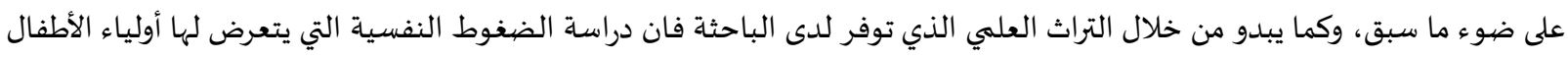

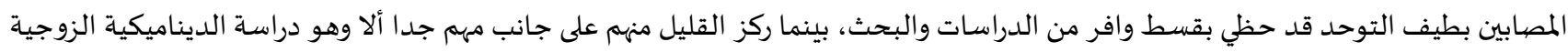

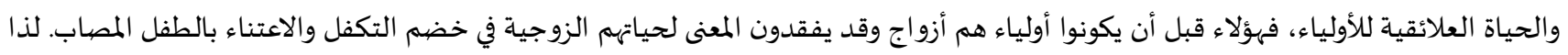

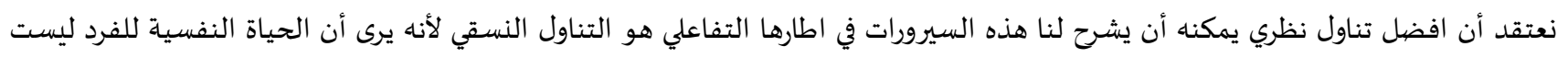

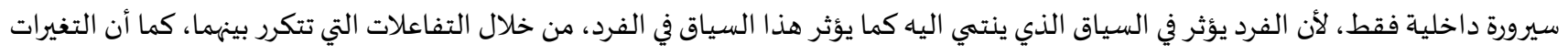
التي تحدث في بنية أي عائلة تؤدي الى حدوث الثرد تغيرات في السلوكات و السيرورات النفسية الد اخلية للأفراد (Minuchin,1998).

الإجراءات الميدانية للدراسة:

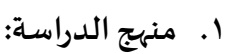

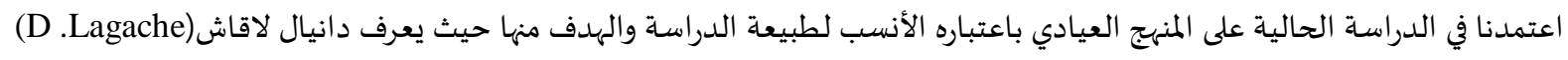

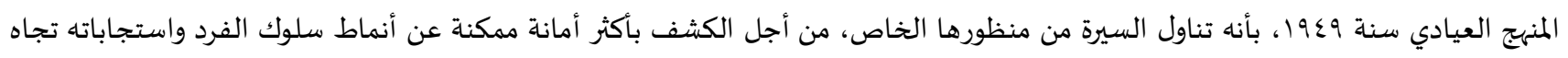

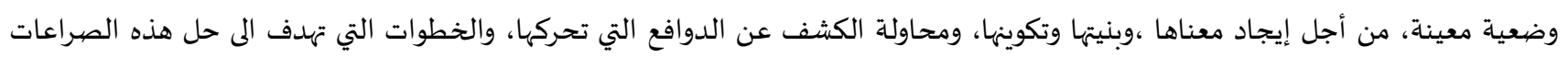

(Reuchlin,1976)

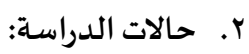

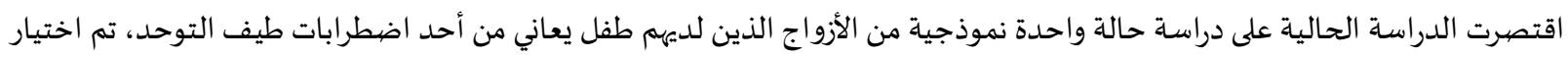

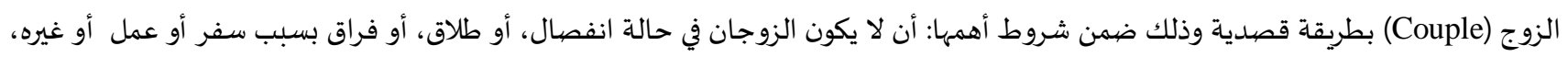

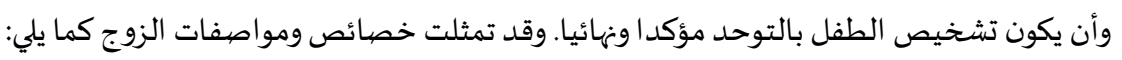
جدول (1): يبين خصائص مواصفات الحالة(الزوج) (Couple)

\begin{tabular}{|c|c|c|c|c|c|c|c|}
\hline الأبناء عداء & السكن & طبيعة & الاقتصلادي & الدراسي & المهنة & السن & الاسم \\
\hline \multirow[t]{2}{*}{03} & \multirow{2}{*}{ مستقل } & \multirow{2}{*}{ تقليدي } & \multirow{2}{*}{ جيد } & جامعي & موظف & سنة 48 & السيد (ج) \\
\hline & & & & جامعية & موظفة & سنة 38 & السيَدَّ(ج) \\
\hline
\end{tabular}

r. أدوات جمع بيانات الدراسة: اعتمدت الدراسة الحالية على المنتهج العيادي وعليه فقد تم استخدام أدواته المتمثلة في: الملاحظة ، والمقابلة العيادية الزوجية، وكذا اختبار سبانييه للتوافق الزواجي. 
تم الاعتماد في هذه الدراسة على الملاحظة البسيطة التي تعرف على أهها ملاحظة السلوك كما يحدث تلقائيا في ظروفه الطبيعية، دون اخضاعها

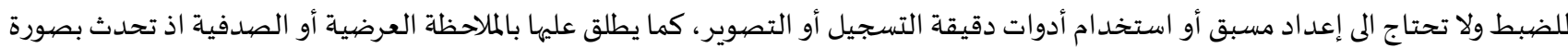

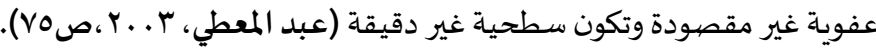
• المقابلة العيادية النصف موجهة: ترى شيلون C.Chiland أن المقابلة العيادية نصف الموجهة ليست حرة ولا مقيدة ، بل تقع بين الاثنين ،حيث يكون فهيها دور الفاحص هو

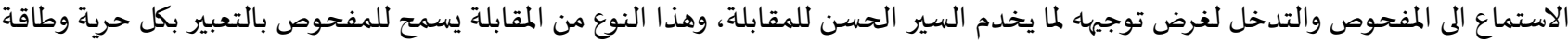

وهي مشجعة للكلام والتحدث (Chiland,1983,P2). تم اجراء المقابلات نصف الموجهة في الدراسة الحالية اعتمادا على دليل مقابلة تم اعداده مسبقا مراعين فيها أهداف الدراسة، كما تمت تغطيتها من خلال إجراء أريع مقابلات زوجية (couple interview) بمعدل مقابلة كل أسبوع برمجت بالاتفاق مع الزوجين وتضمنت المقابلة المحاور التالية:

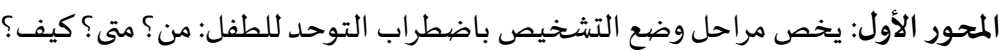
المحور الثاني: يخص تحديد مختلف الأعراض أو السلوكات التي تزعج الأولياء بشدة في الحياة اليومية وتشكل لهم صعوبات فئات في التعامل مع الطفل نفسها أو مع المحيط العام. المحور الثالث: يتعلق بردود أفعال الزوجين اتجاه السلوكات المشكلة والآليات المتبناة من قبل كل زوج لمواجهة الصعيوبات الماتلات الناتجة عنها.

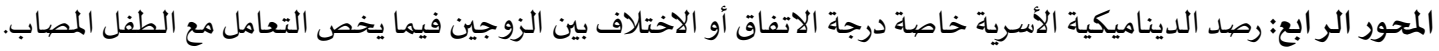

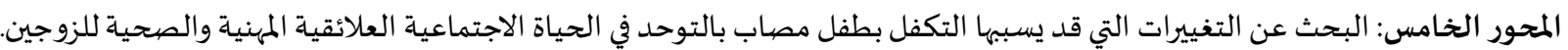

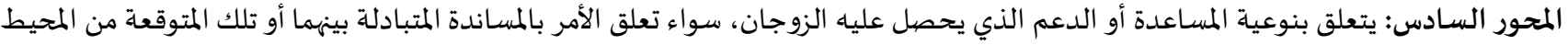
العام (العائلة، الأصدقاء، السلطات...). مقياس التو افق الزواجي لسبانييه:

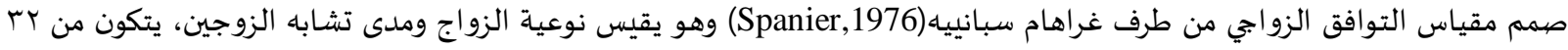

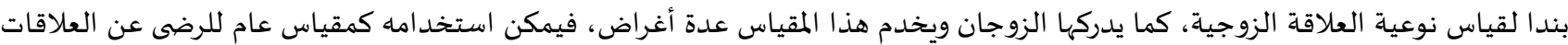

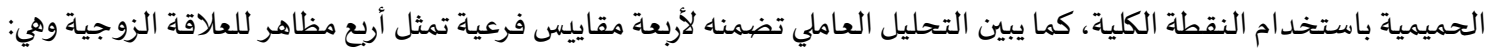

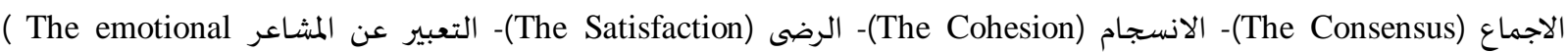

( Gaudeault,1995,P12) expression)

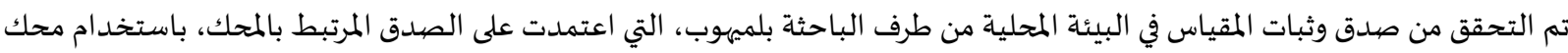

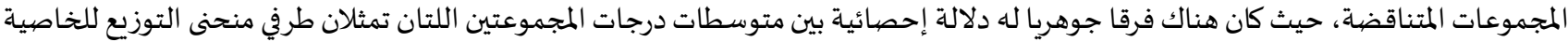

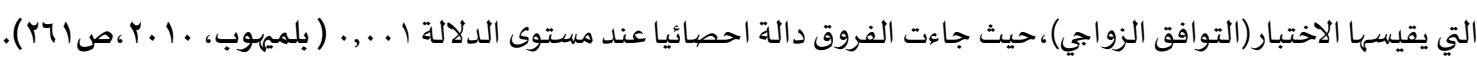
ع. مكان اجراء الدراسة الميدانية:

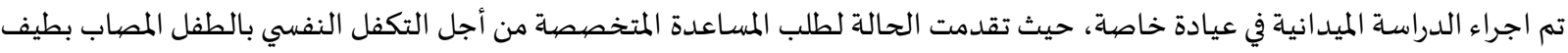

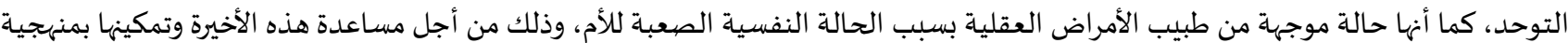
عمل معينة تساعدها على التعامل مع طلفها المصياب.

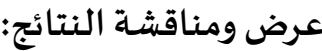

1. أ. عرض وتحليل محتوى المقابلة للحالة (ج)

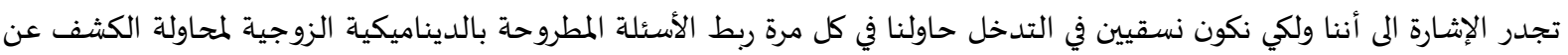

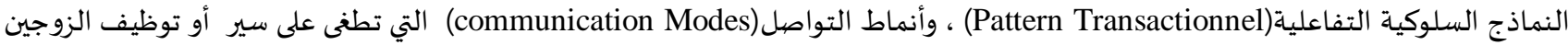
،وإن كان لاضطراب الابن التوحدي علاقة بهذا الأمر أم لا، وذلك من خلال طرح الأسئلة بشكل دائري (Circular) ،دون التركيز على تفاصيل الأحداث

بل على سيروتها. أولاً: تقديم الحالة: 
حالة الزوجين السيد والسيدة (ج)، الزوج ^ع سنة موظف، ذو مستوى تعليمي جامعي، والزوجة مب سنة موظفة في مصلحة استشفائية،

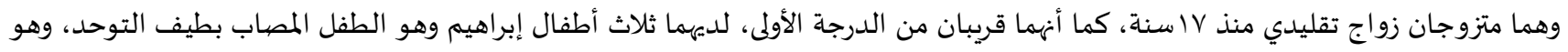

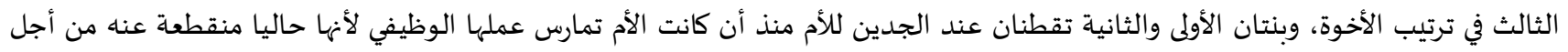

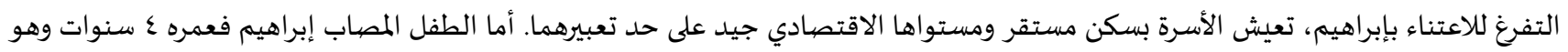

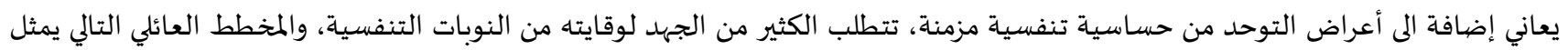

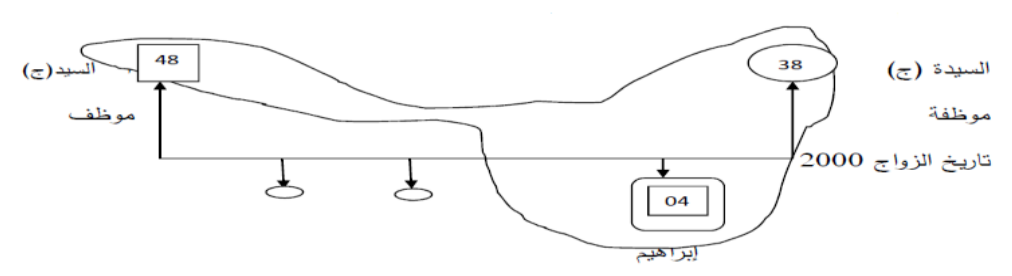

عائلة (ج)

شكل رقم (O1): مخطط عائلي يمثل العائلة (ج)

ثانياً: سير الطلب: Cheminement de la demande

إن مراحل الطلب بدأت عند الزوجين بعد أن لاحظ الوالدان وكذا بعض أفراد العائلة الكبيرة للأم (الجدة والخالة)، أن الطفل إبراهيم متأخر

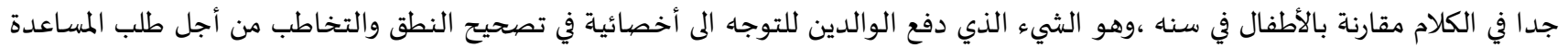

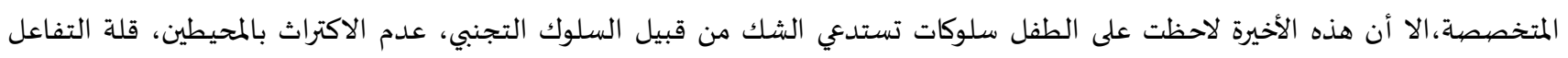

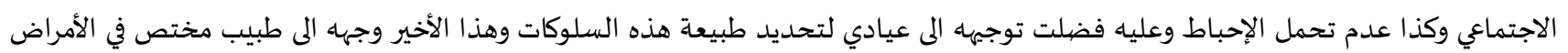
العقلية أين حدد تشخيص التوحد بصورة واضحة ،ونظرا للصعوبة التي كانت تعاني منها الأم في كيفية التعامل مع الطفل وصل الزوجان النهان الى مكتب الباحثة بالعيادة الخاصة.

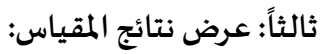
يمكننا تلخيص نتائج السيد والسيدة (ج) على أبعاد سلم التوافق الزواجي كما يلي:

جدول (r): نتائج السيد والسيدة (ج) على أبعاد سلم التو افق الزواجي

\begin{tabular}{|c|c|c|}
\hline السيدة (ج) & السيد (ج) & أبعاد السلم \\
\hline 70$)^{r q}$ & 7.0 or & الاجماع \\
\hline ro/ ${ }^{9}$ & $\mathrm{rol}^{17}$ & الانسجام \\
\hline $0.1^{r 7}$ & $0.1^{r_{0}}$ & الرضا \\
\hline $\mid T^{. \varepsilon}$ & $\mid T^{7}$ & التعبير عن المشاعر \\
\hline $101^{\mathrm{VA}}$ & $101^{11 .}$ & العلامة الكلية \\
\hline
\end{tabular}

من خلال النتائج الكلية للسلم يبدو أن الزوجين (ج)، يعانيان من صعوبات زواجية ،حيث حصل السيد(ج) على علامة كلية تساوي ـ 11 ، بينما

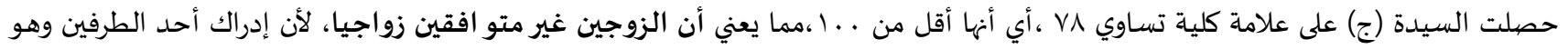

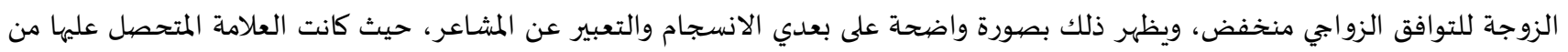
طرف الزوجة أقل من متوسط الدرجات على هذين البعدين ،في حين بلغت علاماتها على البعدين الباقيين وهما الاجماع والرضيا درجة تفوق المتوسط البها بقليل فقط.

السيد (ج) من جهته كانت أدنى علامة له تتعلق ببعد التعبير عن المشاعر، حيث حصل على علامة - من ب ا ، وهي متوسط درجات هذا البعد

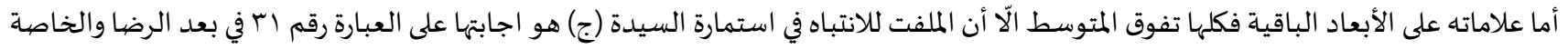

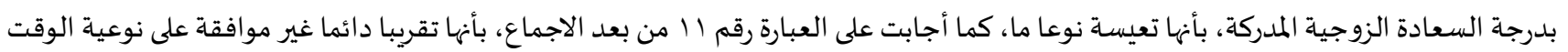
الممضي مع الزوج. 
رابعاً: تحليل نتائج المقابلة والمقياس معا ومناقشـة النتائج:

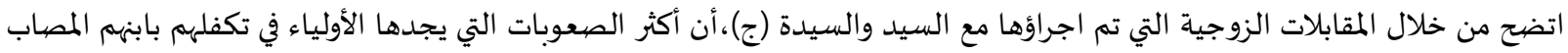

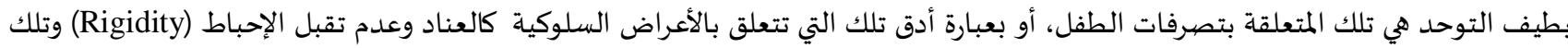

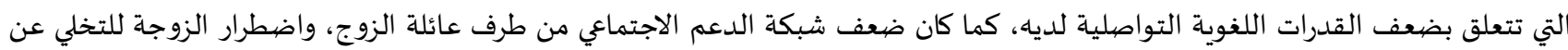

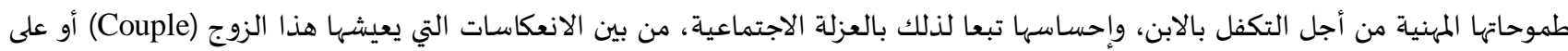
الأقل الزوجة.

أما من حيث الدينامية الزوجية، فقد لمسنا عدة نقاط اختلاف بين الزوجين كعدم اتفاقهما حول التشخيص بالتوحد وحول أسباب السلوكات

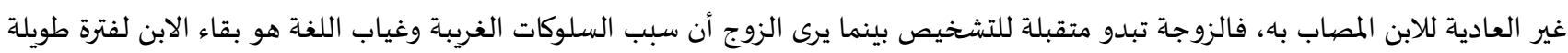

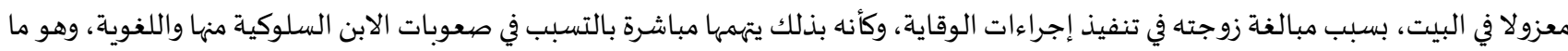

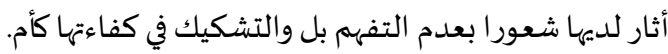

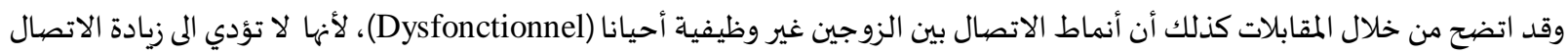
بل الى خفضاه ولا تؤدي الى التكامل(La complementarity ) بل الى التجنب ويظهر ذلك من خلال تصريح الزوجة بأنها حاليا تتفادى الدخول في

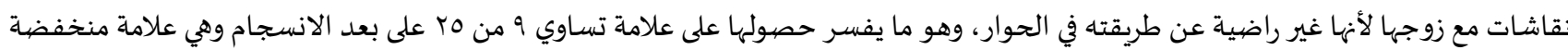

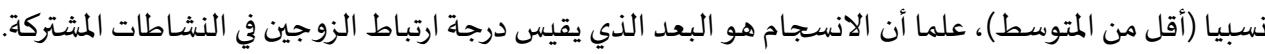

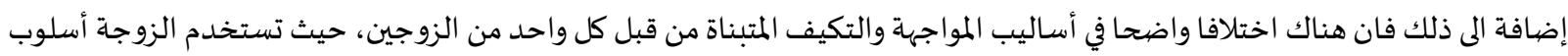
التجنب بينما يفضل الزوج أسلوب المواجهة وحل المشكل عندما يتعلق الأمر بالوضعيات التي تخص الاضطرابـابـات السلوكية أو أو المزاجية للابن.

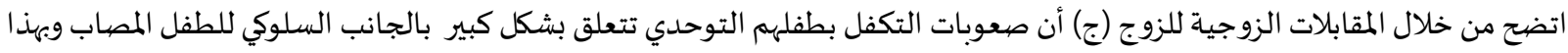

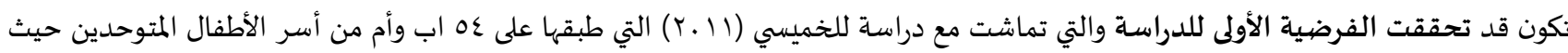

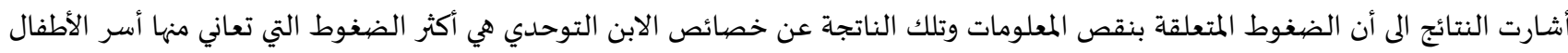

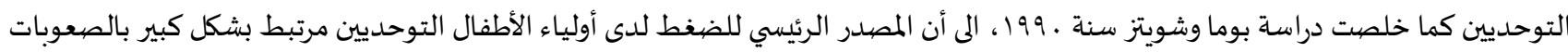

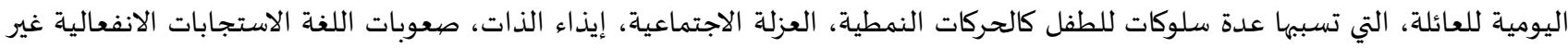

الملائمة (Denis,2013,P35).

بالنسبة لنوعية الحياة الزوجية لأولياء الطفل التوحدي فقد بينت الدراسـة الحالية أن هناك اضطرابات في الدينامية الزوجية وبعض

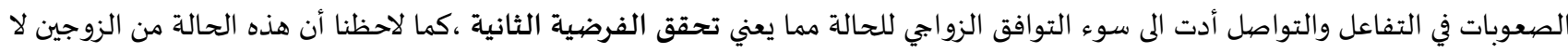

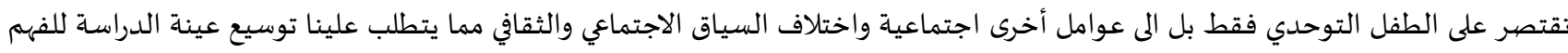

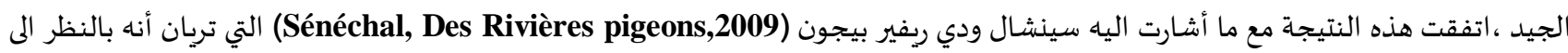

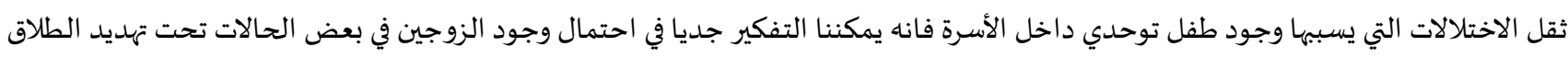

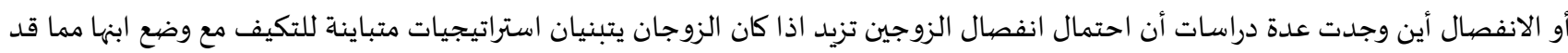

يزيد الهوه بينهما أو يعقد عملية تقاسم الأدوار والمسؤوليات تجاه هذا الطفل(Martin and al, 1993).

الخاتمةة:

تمثل موضوع الدراسة الحالية في تحديد صعوبات التكفل الأولياء بطفل توحدي وانعكاسات تلك الصعوبات على التوافق الزواجي لوالديه، ولتحقيق هذه الأهداف تم استخدام المنهج العيادي ودراسة حالة مع الاعتماد في جمع البيانات على أدوات المنهج العيادي المتمثلة في: الملاحظة- المقابلة

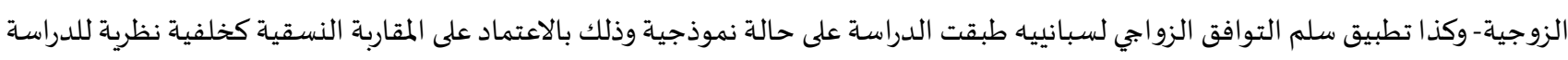

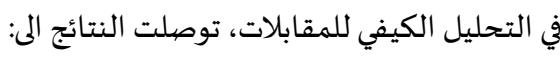

تتعلق صعوبات تكفل لأولياء بطفل مصاب بطيف التوحد بشكل رئيسي بالجانب السلوكي للطفل منها: العناد، وعدم تقبل الإحباط

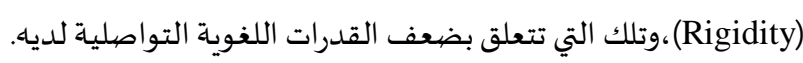

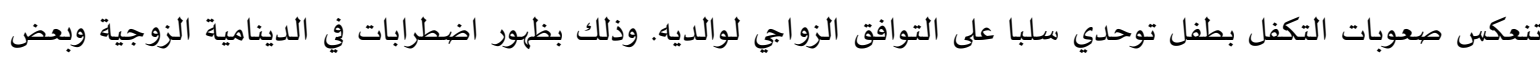

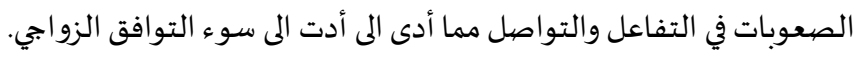

كما خلصنا الى مجموعة من التوصيات أهمها: 


$$
\text { ضرورة الاهتمام أكثر بمعاش الأولياء من قبل المتدخلين بغية الوصهول الى تكفل ناجح بالطفل التوحدي. }
$$

اشراك أسرة أطفال التوحديين في برامج العلاج والتأهيل التي تقدمها المؤسسات المتخصصة ليس فقط لفائدة الطفل إنما للحفاظ على

$$
\text { التوافق الزواجي بينهما. }
$$

الاعتماد على المقاربة النسقية كنموذج تدخل لمساعدة الأطفال التوحديين على التكيف، والعمل معا من أجل تجاوز الاضطرابات

$$
\text { العلائقية التي قد يسبيها وجود الطفل التوحدي. }
$$

القيام ببحوث فيما يتعلق بتأثير التوافق الزواجي والاسري على مدى تقدم الطفل التوحدي في البرامج العلاجية.

$$
\text { ألمراجع: أمراجع العربية: }
$$

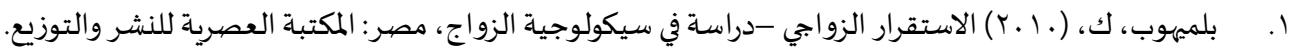

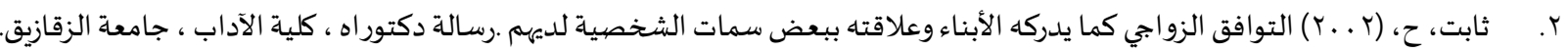

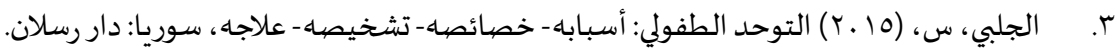

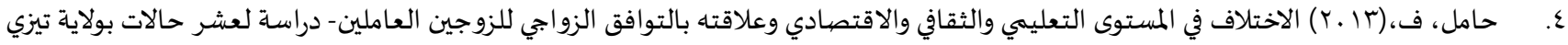

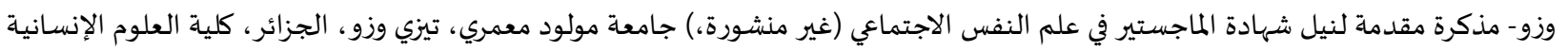
والاجتماعية، قسم علم النفس.

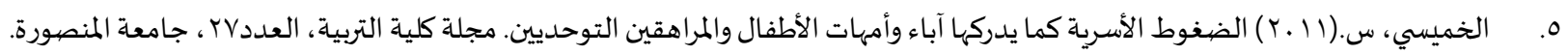

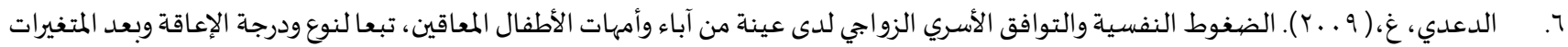

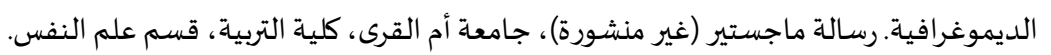

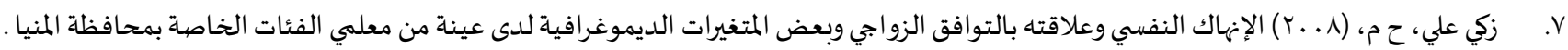

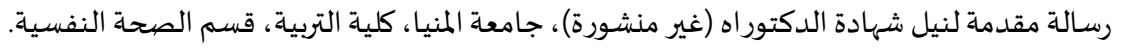

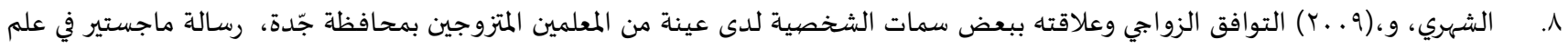

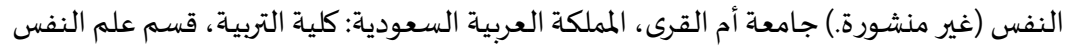

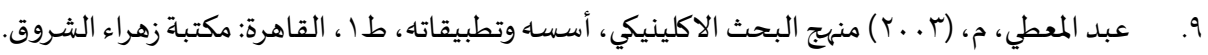

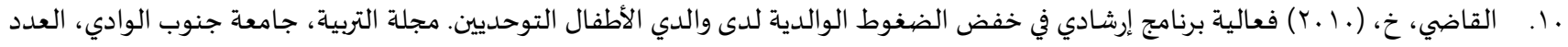

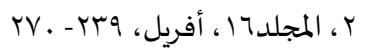
1 ا. كاوجة، م، (ع ا ـا) تمثلات التوافق الزواجي وعلاقته بأساليب المعاملة الزوجية والخلافات الزوجية- دراسة ميدانية مقارنة بين النساء العاملات وغير

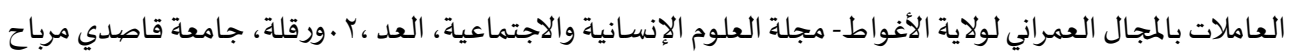
مرسي، ك، (1990) العلاقة الزوجية و الصحة النفسية في الإسلام و علم النفس، الكويت: دار القلم للنشر والتوزيع.

[1] Chiland. C et al, L'entretien clinique, Paris : Presse universitaire France, (1983).

[2] Denis. J, Etre parent d'un enfant autiste: difficultés vécus et répercussions sur sa santé, sa vie personnelle, conjugale, familiale, sociale, et professionnelle. Memoir présent dans le cadre de la maitrise en travail social, Université du Québec, (2013), https://doi.org/10.1522/030569616

[3] Divan. G ., Vajaratkar. V ., Desai, M.U ., Strik Lievers. L \& Patel. V, Challengers coping strategies, and unmet needs of families with a child with autism spectrum disorder in GOA, india autism research , 5(3) (2012), 190-200, https://doi.org/10.1002/aur.1225

[4] DSM-IV, Manuel diagnostique et statistique des troubles mentaux, Texte revisé (2003). Paris : Masson, (1994)

[5] ElkaimI. M, Panorama des thérapies familiales, Paris : Edition du seuil, (1995) 
[6] Erel. O., \& Burman. B., Interrelatedness of marital relations and parent-child relations: A meta-analytic review, Psychological Bulletin, 118(1)(1995), 108-132, https://doi.org/10.1037//0033-2909.118.1.108

[7] Garcin. N \& Moxness. K, L’impact de la nouvelle définition des Troubles du Spectre de l'autisme du DSM-5, Présentation offerte aux membres du Réseau National TEDLe lundi 30 septembre 2013, Centre Gold, (2013).

[8] Gaudreault. A, Etude de qualité de vis de la femme tumorectomies atteinte de cancer de sein, et de la relation du couple. Mémoir présenté comme exigence partielle de la maitrise en psychologie. Trois rivières, Université du Québec, (1995)

[9] Gayda. M. \& Lebovici. S. Les causes de l'autisme et leurs traitements. L'Harmattan, (2000)

[10] Gomes. E \& Pedroso. F.S, Language in autism. In P.C cercisle. (Ed) progress in autism research, (2007), pp. 221-238.

[11] Konstantareas. M. \& Homatidis, Assessing child symptom Severity and stress in parents of autistic children, Journal of child psychology, Psychical, 30 (3)(1988), 459-470, https://doi.org/10.1111/j.14697610.1989.tb00259.x

[12] Lasselin. C \& al, Famille et trouble envahissants du développent (TED) : Facteurs influençant l'impact de la situation de handicap. Le bulletin scientifique de L'ARAPI $\mathrm{N}^{\circ} 29$, (2012)

[13] Magerotte $G$ \& Rogé B. Intervention précoce en autisme : undéfi pour les praticiens. Évol psychiatr, 69(4)(2004), 579- 588, https://doi.org/10.1016/j.evopsy.2003.07.003

[14] Marot. P, Analyse fonctionnelle des stéréotypies d'un enfant porteur d'un Trouble du Spectre Autistique, Mémoire en vue de l'obtention du Diplôme d'État de Psychomotricien, Universite Paul Sabatier Faculté de Médecine Toulouse - Rangueil, (2013)

[15] Martin. P , Papier. C , Mayer. J, La handicape en question : des familles face à découverte du handicap, et à l'accompagnement du jeune enfant à domicile. Université libre de Bruxelles, Ecole de santé publique, Laboratoire d'épidémiologie et de médecine social, Bruxelles, (1993)

[16] Minuchin. S., Où est la famille en thérapie familiale narrative Le Journal de thérapie conjugale et familiale, 24, 397-403, (1998)

[17] Paquette. D. \& Bigras. M., The risky situation: A procedure for assessing the father-child activation relationship. In L. A. Newland, H.S. Freeman, \& D.D. Coyl (Eds.), Emerging Topics on Father Attachment: Considerations in Theory, Context and Development, (2011), pp. 32-49, London: Routledge.

[18] Reuchlin. M, Les Méthode en psychologie- Que Sais-je ? : PUF, (1976)

[19] Rongeul. F, Famille en crise, approche systémique des relation humaines, Collection thérapie et systémique, (2003)

[20] Satir. V, Thérapie de couple et de la famille, Paris : Edition des clés de Brower, (1995)

[21] Sénéchal. C., \& des Rivières-Pigeon. C., Impact de l'autisme sur la vie des parents. Santé mentale au Québec, 34(1)(2009), 245-260, https://doi.org/10.7202/029772ar

[22] Stierlin. H (SD), Le premier entretien familial : Théorie- Pratique- Exemple. Traduction de jaques jeudi, Ed : Pierre Delage 


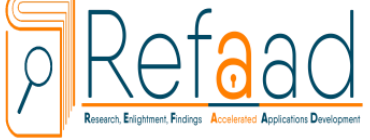

رفاد للدراسات والأبحاث

www.refaad.com
المجلة الدولية للدراسـات التربوية والنفسية

e-ISSN 2520-4149, p-ISSN 2520-4130

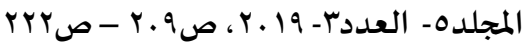

https://doi.org/DOI:10.31559/EPS2019.5.3.1
المجلة الدولية للدراسات

الثربوية والنفسية

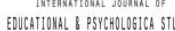

\title{
The Marital Adjustment in the Presence of Autistic Child: Systemic Study of Case of Family
}

\section{Samia Rahal}

Hassiba Benbouali University- BChlef- Algeria

samiapsy@gmail.com

\begin{abstract}
The current study aims to highlight of autistic children's parents and its difficulties in care, and their implications on the marital adjustment for them. For this purpose, we will attempt to present a case of families with autistic children using the systematic approach for intervention.

We based on the clinical method and its materials which are: observation, semi-clinical interviews couple, and marital adjustment scale.

The results of the study indicate that the difficulties of ensuring that a child with a spectrum autism reflect negatively on the marital adjustment of his parents
\end{abstract}

Keywords: Marital adjustment, Autism, systematic approach.

\section{References:}

[1] 'bd Ạlm ț̣. M, Mnhj Ạlbḥtḥ Ạlạklynyky, Ạ̉ssh Wtṭbyqạth, Ṭ1, Ạlqạhrh: Mktbẗ Zhrạ’ Ạlshrwwq, (2003).

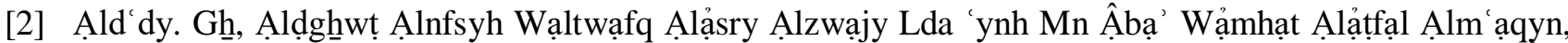

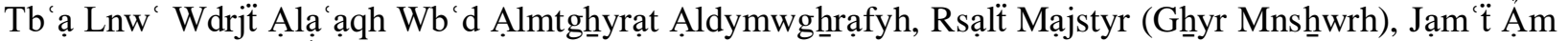
Ạlqra, Klÿ̈ Ạltrbyh, Qsm 'lm Ạlnfs, (2009).

[3] Ạljlby. S, Ạltwḥd Ạlț̣wly: Ạ̉sbạbh- Kḥṣậș̣h- Tshkhḳyṣh- 'lạjh, Swryạ: Dạr Rslạn, (2015).

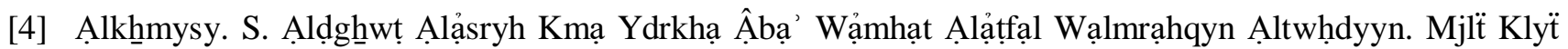
Ạltrbyh, Ạl'dd27, Jạm ‘̈ Ạlmnṣwrh, (2011).

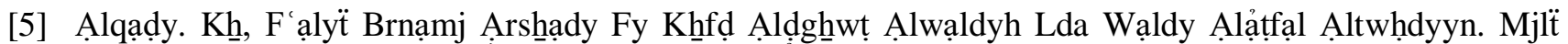
Ạltrbyh, Jạm ‘̈̈ Jnwb Ạlwạdy, Ạl’dd 2, Ạlmjld16, Ạfryl, 239- 270, (2010).

[6] Ạlshhhry. W, Ạltwạfq Ạlzwạjy W'lạqth Bb'ḍ Smạt Ạlsḥkhș̣h Lda 'ynh Mn Ạlm lmyn Ạlmtzwjyn

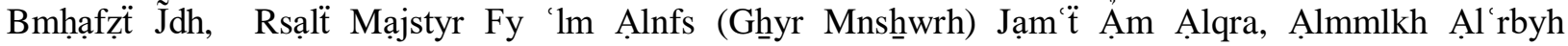
Ạls 'wdyh: Klÿ̈ Ạltrbyh, Qsm 'lm Ậlnfs, (2009).

[7] Blmyhwb. K, Ạlạstqrạr Ạlzwạjy -Drạsh Fy Sykwlwjyë Ạlzwạj, Mṣr: Ạlmktbh Ạl ’ṣryh Llnsḥr Wạltwzyc, (2010).

[8] Chiland. C et al, L'entretien clinique, Paris : Presse universitaire France, (1983). 
[9] Denis. J, Etre parent d'un enfant autiste: difficultés vécus et répercussions sur sa santé, sa vie personnelle, conjugale, familiale, sociale, et professionnelle. Memoir présent dans le cadre de la maitrise en travail social, Université du Québec, (2013), https://doi.org/10.1522/030569616

[10]Divan. G ., Vajaratkar. V ., Desai, M.U ., Strik Lievers. L \& Patel. V, Challengers coping strategies, and unmet needs of families with a child with autism spectrum disorder in GOA, india autism research , 5(3) (2012), 190-200, https://doi.org/10.1002/aur.1225

[11] DSM-IV, Manuel diagnostique et statistique des troubles mentaux, Texte revisé (2003). Paris : Masson, (1994)

[12] ElkaimI. M, Panorama des thérapies familiales, Paris : Edition du seuil, (1995)

[13] Erel. O., \& Burman. B., Interrelatedness of marital relations and parent-child relations: A meta-analytic review, Psychological Bulletin, 118(1)(1995), 108-132, https://doi.org/10.1037//0033-2909.118.1.108

[14] Garcin. N \& Moxness. K, L'impact de la nouvelle définition des Troubles du Spectre de l'autisme du DSM-5, Présentation offerte aux membres du Réseau National TEDLe lundi 30 septembre 2013, Centre Gold, (2013).

[15] Gaudreault. A, Etude de qualité de vis de la femme tumorectomies atteinte de cancer de sein, et de la relation du couple. Mémoir présenté comme exigence partielle de la maitrise en psychologie. Trois rivières, Université du Québec, (1995)

[16] Gayda. M. \& Lebovici. S. Les causes de l'autisme et leurs traitements. L'Harmattan, (2000)

[17] Gomes. E \& Pedroso. F.S, Language in autism. In P.C cercisle. (Ed) progress in autism research, (2007), pp. 221-238.

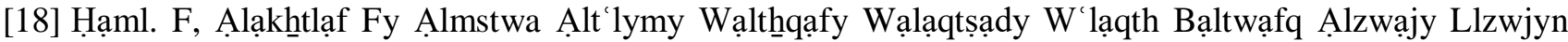
Ạl'ạmlyn- Drạsẗ L'shr Hạạt Bwlạyẗ Tyzy Wzw- Mdhnkrh Mqdmh Lnyl Sh̆hạdẗ Ạlmạjstyr Fy 'lm Ạlnfs

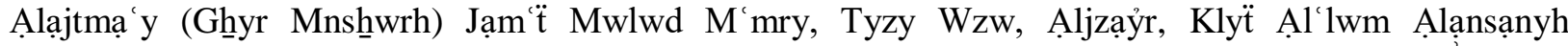
Wạlạjtmạ yh, Qsm 'lm Ạlnfs, (2013).

[19] Kạwjh. M, Tmthlạt Ạltwạfq Ạlzwạjy W'lạqth Bạ̉sạlyb Ạlm‘ạmlh Ạlzwjyh Wạlkhlạfạt Ạlzwjyh- Drạsh Mydạnyh Mqạrnh Byn Ạlnsạ’ Ạl ạmlạt Wghyr Ạl'ạmlạt Bạlmjạl Ạl'mrạny Lwlạyt Ạlạ̉ghnwạt- Mjlt Ạl' lwm Ạlạnsạnyh Wạlạjtmạ 'yh, Ạl'd ,02wrqlh, Jạm ‘̈̉ Qạṣdy Mrbạh, (2014).

[20] Konstantareas. M. \& Homatidis, Assessing child symptom Severity and stress in parents of autistic children, Journal of child psychology, Psychical, 30 (3)(1988), 459-470, https://doi.org/10.1111/j.14697610.1989.tb00259.x

[21] Lasselin. C \& al, Famille et trouble envahissants du développent (TED) : Facteurs influençant l'impact de la situation de handicap. Le bulletin scientifique de L'ARAPI ${ }^{\circ} 29$, (2012)

[22] Magerotte G \& Rogé B. Intervention précoce en autisme : undéfi pour les praticiens. Évol psychiatr, 69(4)(2004), 579- 588, https://doi.org/10.1016/j.evopsy.2003.07.003

[23] Marot. P, Analyse fonctionnelle des stéréotypies d'un enfant porteur d'un Trouble du Spectre Autistique, Mémoire en vue de l'obtention du Diplôme d'État de Psychomotricien, Universite Paul Sabatier Faculté de Médecine Toulouse - Rangueil, (2013) 
[24] Martin. P , Papier. C , Mayer. J, La handicape en question : des familles face à découverte du handicap, et à l'accompagnement du jeune enfant à domicile. Université libre de Bruxelles, Ecole de santé publique, Laboratoire d'épidémiologie et de médecine social, Bruxelles, (1993)

[25] Minuchin. S., Où est la famille en thérapie familiale narrative Le Journal de thérapie conjugale et familiale, 24, 397-403, (1998)

[26] Mrsy. K, Ạl'lạqh Ạlzwjyh W Ạlṣḥh Ạlnfsyh Fy ẠlạSlạm W 'lm Ạlnfs, Ạlkwyt: Dạr Ạlqlm Llnsḥr Wạltwzy', (1995).

[27] Paquette. D. \& Bigras. M., The risky situation: A procedure for assessing the father-child activation relationship. In L. A. Newland, H.S. Freeman, \& D.D. Coyl (Eds.), Emerging Topics on Father Attachment: Considerations in Theory, Context and Development, (2011), pp. 32-49, London: Routledge.

[28] Reuchlin. M, Les Méthode en psychologie- Que Sais-je ? : PUF, (1976)

[29] Rongeul. F, Famille en crise, approche systémique des relation humaines, Collection thérapie et systémique, (2003)

[30] Satir. V, Thérapie de couple et de la famille, Paris : Edition des clés de Brower, (1995)

[31] Sénéchal. C., \& des Rivières-Pigeon. C., Impact de l'autisme sur la vie des parents. Santé mentale au Québec, 34(1)(2009), 245-260, https://doi.org/10.7202/029772ar

[32] Stierlin. H (SD), Le premier entretien familial : Théorie- Pratique- Exemple. Traduction de jaques jeudi, Ed : Pierre Delage

[33] Thạbt. H, Ạltwạfq Ạlzwạjy Kmạ Ydrkh Ạlạ̉bnạ’ W' lạqth Bb ‘̣̣ Smạt Ạlsḥkhnṣyh Ldyhm .Rsạlt Dktwrạh , Klÿ̇ Ạlậdạb , Jạm ‘̈ Ạlzqạzyq, (2002).

[34] Zky 'ly. Ḥ M, Ạlậạak Ạlnfsy W' lạqth Bạltwạfq Ạlzwạjy Wb’ạ Ạlmtghِyrạt Ạldymwghrạfyh Lda 'ynh

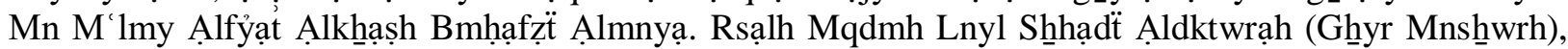
Jạm ‘̈ Ạlmnyạ, Klyẗ Ạltrbyh, Qsm Ạlșḥh Ạlnfsyh, (2008). 